Anggia Putri, Wirman / PENGARUH CAR, ROA DAN NPF TERHADAP PEMBIAYAAN MURABAHAH

\title{
PENGARUH CAR, ROA DAN NPF TERHADAP PEMBIAYAAN MURABAHAH
}

\author{
Anggia Putri \\ Universitas Singaperbangsa Karawang \\ 1710631030034@student.unsika.ac.id \\ Wirman \\ Universitas Singaperbangsa Karawang \\ wirman@feb.unsika.ac.id
}

\begin{abstract}
This research aims to find out how the impact of Capital Adequacy Ratio (CAR), Return On Assets (ROA) and Non Performing Finance (NPF) on Murabahah Financing at Islamic Business Banks registered with Bank Indonesia for the 2015-2019 period. The population used is all Sharia Business Banks that have been registered with the Financial Services Authority (OJK) for the 2015-2019 period. The sample taken is 11 Sharia Business Banks by applying the purposive sampling method. The data applied is secondary data in the form of financial reports obtained from the respective websites of each bank. The method used is quantitative analysis using multiple regression. The results of the study stated that CAR and NPF had no effect on murabahah financing while the ROA variable had an effect on murabahah financing. Meanwhile, simultaneously, the three variables CAR, ROA, and NPF have a significant effect on murabahah financing.
\end{abstract}

Keywords : CAR, ROA, NPF dan Pembiayaan Murabahah.

\section{PENDAHULUAN}

Perbankan industri memiliki peran yang amat penting dalam perekonomian sebagaimana diatur UU pasal 1 ayat 2 Nomor 10 Tahun 1998 perihal UU perubahan Nomor. 7 Tahun 1992 perihal yang mengungkapkan bahwasanya perbankan ialah badan usaha yang memiliki tugas mengumpulkan dana masyarakat dengan format kredit maupun pinjaman dalam format lainnya yang dapat membuat memajukan kualitas kehidupan rakyat. (Simatupang, 2019)

Penyebaran suatu biaya dalam Bank Umum Syariah memiliki kedua produksi yang penting yakni dana rancangan berbagi hasil dan dana rancangan pembelian dan penjualan murabahah. Salah satu tujuan dari dana yang dilaksanakan oleh bank bisnis syariah yakni menempuh laba bersih maksimum. Keuntungan adalah perbedaan antara pendapatan dan biaya.
Oleh sebab itu, bank semestinya bisa mengoptimalkan penghasilan dengan biaya tertentu. (Setyaji, 2018)

Murabahah ialah kesepakatan barang yang akan dijual dalam mengungkapkan perolehan harga serta manfaat yang disetujui pembeli dan penjual. Perihal perbedaan dari penjualan murabahah ialah bahwa penjualan dengan terang menyampaikan pernyataan bahwa pembelian biaya biaya produk dan seberapa banyak yang dia inginkan dari keunggulan. (Nurhayati \& Wasilah, 2019) 
Tabel 1 Pembiayaan Menurut Berbagai Macam Akad Bank Umum Syariah 2015 - 2019 (dalam miliaran rupiah)

\begin{tabular}{|c|c|c|c|c|c|}
\hline \multirow[t]{2}{*}{ Jenis Akad } & \multicolumn{5}{|c|}{ Tahun } \\
\hline & 2015 & 2016 & 2017 & 2018 & 2019 \\
\hline Mudharabah & $\mathrm{Rp} 168.516$ & $\mathrm{Rp} 156.256$ & Rp 151.719 & Rp 146.247 & $\operatorname{Rp} 240.606$ \\
\hline Musyarakah & $\operatorname{Rp} 652.316$ & Rp 774.949 & Rp 739.562 & $\operatorname{Rp} 737.620$ & Rp 1.121.004 \\
\hline Murabahah & Rp 4.491.697 & Rp 5.053.764 & Rp 5.097.883 & $\operatorname{Rp} 6.204 .187$ & $\operatorname{Rp} 7.457 .774$ \\
\hline Salam & $\mathrm{Rp} 15$ & $\mathrm{Rp} 14$ & Rp 14 & 0 & 0 \\
\hline Istisna & Rp 11.135 & Rp 9.423 & Rp 10.894 & Rp 23.115 & $\operatorname{Rp} 67.178$ \\
\hline Ijarah & Rp 6.175 & Rp 6.763 & Rp 7.302 & Rp 24.204 & $\operatorname{Rp} 41.508$ \\
\hline Qardh & $\mathrm{Rp} 123.588$ & $\mathrm{Rp} 145.865$ & $\mathrm{Rp} 154.506$ & $\mathrm{Rp} 168.200$ & $\mathrm{Rp} 176.856$ \\
\hline Multijasa & Rp 311.729 & Rp 515.523 & Rp 548.520 & Rp 774.663 & Rp 838.394 \\
\hline Total & Rp 5.765.171 & Rp 6.662 .556 & Rp 6.710.400 & Rp 8.078.236 & Rp 9.943.320 \\
\hline
\end{tabular}

Sumber : Statistik Perbankan Syariah bulan Desember tahun 2019

Menurut data Statistik Perbankan Syariah pada bulan Desember tahun 2019, menampilkan bahwa yang paling diminati yaitu pembiayaan murabahah dalam menyalurkan dananya dengan prinsip penjualan dan pembelian dibandingi dengan berbagai macam jenis akad biaya lain.

Otoritas pembiayaan murabahah yang sudah diteruskan sehingga bisa diberi pengaruh unsur-unsur internal bank dan eksternal bank. Aspek yang bisa memberi pengaruh jumlah pembiayaan yang disengaja merupakan sisi eksternal, seperti kehidupan usaha. Dan aspek yang dapat memengaruhi total pembiayaan murabahah yang disalurkan pun merupakan faktor dari internal perusahaan. Untuk mengamati keadaan internal perusahaan bisa diperhatikan dari CAR, ROA dan NPF.

Untuk mengevaluasi kesehatan bank sebagai salah satu aspek, dalam melakukan fungsi bank sepatutnya mempertahankan rasio kecukupan modal untuk menambah kelola asetnya agar menerima profit. Jika nilai CAR semakin tinggi, maka bisa semakin bagus kesanggupan bank untuk menyungguhkan risiko masing-masing aset pembiayaan yang sangat berisiko dan jikalau meningkatnya nilai CAR, maka bank sanggup membiayai aktivitas operasional. Dalam kedudukan kecukupan modal yang bagus dan kesanggupan untuk membiayai aktivitas operasi yang dimiliki oleh bank operasioanl, investasi yang dikembalikan akan menampilkan produktivitas semua biaya perusahaan, baik pinjaman modal taupun ekuitas pemilik. Hal ini, ROA diaplikasikan untuk mengendalikan daya guna operasi perusahaan secara menyeluruh. Dengan meningkatkan pembiayaan, risiko pembiayaan masalah juga tak bisa terhindarkan. NPF diterapkan untuk mengenal total dana yang mempunyai masalah di bank. Jika kian banyak NPF, karenanya akan semakin besar pembiayaan bermasalah. Ini membuat bank seharusnya mengoptimalkan evaluasi kepada pelanggan yang menerima distribusi dana. (Nahrawi, 2017a)

Dari penelitian sebelumnya, ditemukan adanya pengaruh positif dan signifikan dalam CAR dan NPF kepada pembiayaan murabahah menurut (Wardiantika \& Kusumaningtias, 2014), sedangkan ditemukannya tidak berpengaruh dalam ROA terhadap pembiayaan murabahah menurut (Mizan, 2017). Berdasarkan uraian tersebut adanya ketidak pastian, maka diperlukan penelitian ulang mengenai analisis rasio yang mempengaruhi pembiayaan murabahah. Jadi bisa disimpulkan pada penelitian ini yaitu agar mengetahui Capital Adequacy Ratio, Return On Asset dan Non Performing Financing apakah berpengaruh atau tidak terhadap pembiayaan murabahah. 


\section{KAJIAN PUSTAKA PENGEMBANGAN HIPOTESIS}

DAN

\section{Pembiayaan Murabahah}

Murabahah ialah instrument pembiayaan yang menyetujui pihak bank syariah agar memberitahukan terhadap nasabah mengenai pecapaian harga aset dan keuntungan yang dikenakan. Pembiayaan murabahah bisa didapat dengan melihat jumlah pembiayaan murabahah yang diberikan pada bank syariah.(Mahardika, 2015). Alasan Murabahah sinkron dengan syariah yakni kesepakatan antara penjualan dan pembelian dimana harga pokoknya mengalami ialah profit dari penjualan produk. Sangat bertentangan dengan penerapan bunga riba dimana nasabah ingin meminjam uang untuk membeli produk, lalu pinjaman tersebut harus kembali dilunasi lebih.

Pembeli berwenang membatali kemauan untuk menyepakati apabila biaya yang ditemukan oleh penjual tak sinkron dengan kemauan. Transaksi produk ini dapat dilaksanakan dengan lunas atau hutang, namun mesti sesuai perjanjian hingga tak dibatasi upaya kredit.

\section{Pengaruh CAR Terhadap Pembiayaan Murabahah}

CAR mempunyai tujuan agar menentukan bahwa sekiranya dalam kegiatan bank akan mengalami rugi, karenanya modal yang tersedia oleh bank akan sanggup menutupi rugi. (Aziza \& Mulazid, 2017). CAR ini menunjukkan jumlah banyaknya aset yang memuat risiko yang dibiayai dari modal dan dana sendiri dari sumber diluar bank. (Risiko et al., 2015). CAR ialah perbandingan yang menunjukan segala aktivitas bank memuat risiko berpatisipasi yang dibayar dari biaya ekuitas bank. CAR memiliki pengaruh positif pada pembiayaan. Jika CAR semakin tinggi, maka bisa berpengaruh pada pembiayaan yang juga mengalami kenaikan. (Mizan, 2017).

Dalam kedudukan kecukupan modal yang bagus dan kesanggupan untuk membiayai aktivitas operasi yang dimiliki oleh bank operasional, investasi yang dikembalikan akan menampilkan produktivitas semua biaya perusahaan, baik pinjaman modal ataupun ekuitas pemilik.

H1 : CAR berpengaruh terhadap Pembiayaan Murabahah

\section{Pengaruh ROA Terhadap Pembiayaan Murabahah}

Tujuan ROA ialah menampilkan berapa banyak bank yang mengoperasikan kegiatan bisnis dan mengukur kapasitas bank untuk mewujudkan laba dari pengelolaan dana yang di investasikan. Apabila nilai ROA semakin besar, maka bank akan semakin efisien dalam mengatur biaya hingga menghasilkan profit.(Studi et al., 2013). ROA yaitu gambaran dari produktivitas bank dalam mengelola dana hingga memperoleh profit. Maka, ROA selalu digunakan oleh pihak manajemen atas agar dapat memperbaiki berbagai unit usaha di suatu badan usaha multinasional.

Apabila nilai ROA yang dimiliki perusahaan tinggi maka akan kian bagus performa perusahaan dalam menghasilkan profit. Akan tetapi, jika nilai ROA yang dimiliki perusahaan sedikit maka perfoma perusaahn akan tidak bagus.Profit bersih ini ialah profit sesudah pajak (pada laporan keuangan) disebut pula yaitu profit tahun berjalan. (Murabahah et al., 2017)

H2 : ROA berpengaruh terhadap Pembiayaan Murabahah

\section{Pengaruh NPF Terhadap Pembiayaan Murabahah}

NPF yaitu situasi dimana nasabah telah tak memiliki visi pembayaran atau segala keharusannya dengan bank sebagaimana yang sudah dijanjikan. Kredit bermasalah sesuai dengan ketetapan Bank Indonesia yakni pinjaman yang di klasifikasikan dalam angsuran pokok kurang lancar, diragukan dan macet. Dalam LKS, kredit bermasalah selalu dikenal sebagai pembiayaan yang mengalami permasalahan. (Sa'diyah, 2019). Rasio masalah pembiayaan pada total pembiayaan dibayarkan dengan bank syariah. Kerentanan NPF di bank syariah disebut biaya bermasalah. 
Pembiayaan bermasalah yakni biaya yang diberikan oleh bank namun nasabah tidak sesuai dan tidak bisa melaksanakan cicilan dengan perjanjian yang sudah dilegalisasi. NPF ditemukan melalui perhitungan biaya non lancar pada jumlah biayaan. Jika nilai NPF sedikit, maka bank akan kian memperoleh profit. Namun apabila nilai NPF tinggi, bank akan rugi yang mengakibatkan kredit macet.

Keadaan nasabah yang tidak mampu melunasi kewajibannya kepada bank yang sudah dijanjikannya atau yang bisa disebut Non Performing Financing (NPF). Jika nilai NPF semakin meningkat, maka akan semakin tinggi nasabah gagal bayar untuk memberikan pembiayaan murabahah.(Nafidzatun et al., 2020)

H3 : NPF berpengaruh terhadap Pembiayaan Murabahah

\section{METODOLOGI PENELITIAN Populasi dan Sampel}

Populasi berasal dari laporan keuangan tahunan dengan 11 Bank Umum Syariah tahun 2015-2019. Pengambilan sampel dengan mengaplikasikan purpose sampling. Sumber data penelitian data sekunder yang diambil dari situs web setiap Bank. Berdasarkan kriteria Bank Umum Syariah untuk mempunyai kelengkapannya memenuhi data prasyarat untuk dihasilkan sampel yang layak dengan penelitian ini ada 11 Bank Usaha Syariah sehingga jumlah semua data yang didadikan sampel adalah 55 data. Metode analisis yang dipergunakan terdiri dari analisis regresi linier berganda, uji hipotesis, uji asumsi klasik menggunakan aplikasi SPSS 21 dalam pengolahan datanya.

\section{HASIL DAN PEMBAHASAN Uji Normalitas}

Tujuan uji ini ialah untuk menunjukkan data yang digunakan pada variabel dependen dan independen.

Tabel 2. Hasil Uji Normalitas

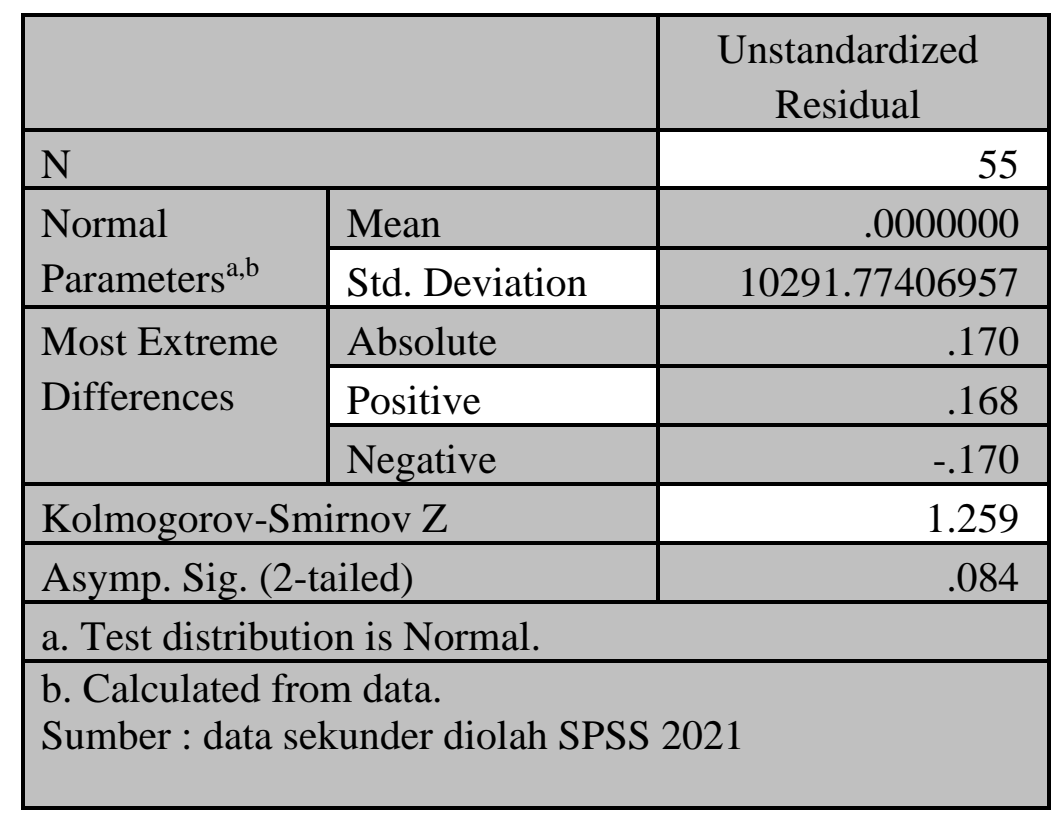

Hasil pengujian dapat diperhatikan ditabel 2, nilai K-S yaitu 1.259 dan signifikasi $0.084>$ 0.05 , maka ditarik kesimpulan data pada penelitian tersebar dengan normal. sudah berdistribusi normal.

\section{Uji Multikolinearitas}

Multikolinearitas uji ini menunjukkan terdapat kesamaan maupun tidaknya antar variabel independen pada model. 


\section{Tabel 3. Hasil Uji Multikolinearitas}

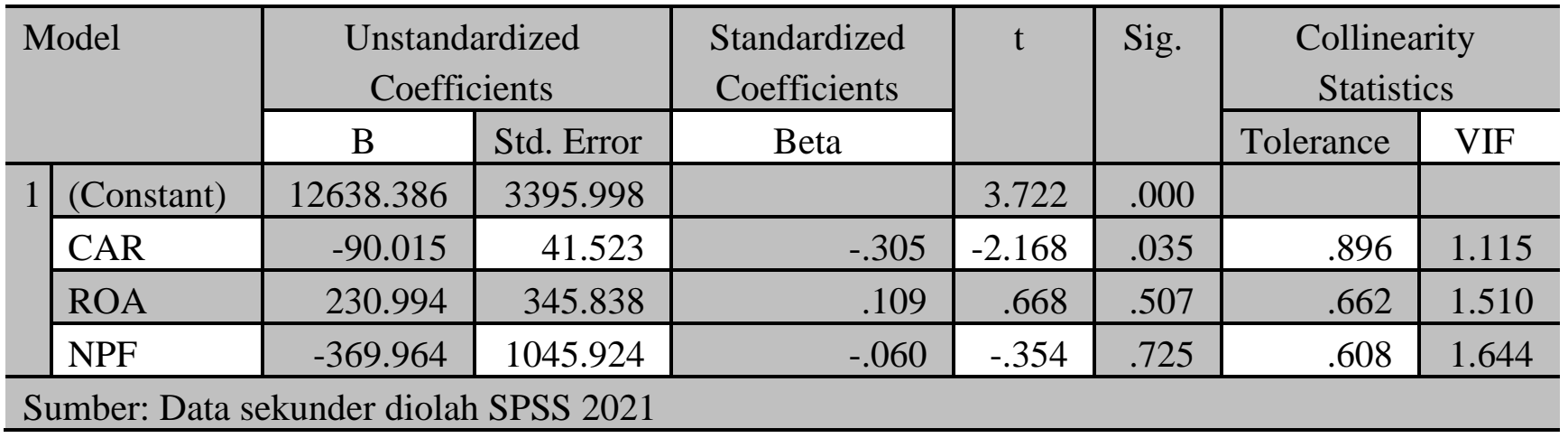

Hasil pengujian terlihat bahwa Variance Inflation Factor (VIF) dari CAR sebesar 1.115 $<$ 10. Nilai VIF dari ROA yakni $1.510<10$, nilai VIF untuk NPF yakni $1.644<10$. Jadi hasil dari penelitian ini tidak memperoleh multikolinearitas.

\section{Uji Heteroskedastisitas}

Heteroskedastisitas uji ini ialah menunjukkan terjadinya ketidaksamaan suatu variance residual periode pengamatan. Dalam Heteroskedastisitas ini memakai uji glejser.

Tabel 4. Hasil Uji Glejser

\begin{tabular}{|c|c|c|c|c|c|c|}
\hline \multicolumn{2}{|c|}{ Model } & \multicolumn{2}{|c|}{ Unstandardized Coefficients } & \multirow{2}{*}{$\begin{array}{c}\text { Standardized } \\
\text { Coefficients }\end{array}$} & \multirow[t]{2}{*}{$\mathrm{t}$} & \multirow[t]{2}{*}{ Sig. } \\
\hline & & $\mathrm{B}$ & Std. Error & & & \\
\hline \multirow[t]{4}{*}{1} & (Constant) & 7557.495 & 2192.669 & & 3.447 & .001 \\
\hline & CAR & -20.829 & 26.810 & -.114 & -.777 & .441 \\
\hline & ROA & 106.388 & 223.294 & .081 & .476 & .636 \\
\hline & NPF & 304.907 & 675.314 & .080 & .452 & .654 \\
\hline
\end{tabular}

Sumber: data sekunder diolah SPSS 2021

Hasil didapatkan bahwa variable independent yaitu CAR, ROA dan NPF > 0.05 sehingga tidak signifikan, dan hasil tabel menunjukkan heteroskedastisitas bebas pada model regresi.

\section{Uji Autokorelasi}

Autokoresi uji ini menunjukkan adanya korelasi atau tidak pada periode tertentu di variabel pengganggu dengan variabel sebelumnya.

Tabel 5. Hasil Uji Autokorelasi

\begin{tabular}{|l|c|r|r|r|r|}
\hline Model & $\mathrm{R}$ & $\begin{array}{c}\mathrm{R} \\
\text { Square }\end{array}$ & $\begin{array}{l}\text { Adjusted } \\
\text { R Square }\end{array}$ & $\begin{array}{c}\text { Std. Error of } \\
\text { the Estimate }\end{array}$ & $\begin{array}{c}\text { Durbin- } \\
\text { Watson }\end{array}$ \\
\hline 1 & $.456^{\mathrm{a}}$ & .208 & .160 & 5587.63867 & 1.747 \\
\hline
\end{tabular}


Sumber : data sekunder diolah SPSS 2021

Jika dilihat tabel, nilai (DW) ialah 1.747 dan akan dibandingkan dengan $\mathrm{DW}_{\text {tabwl }}(\mathrm{k}, \mathrm{n})$ jadi $(4,55)$, dan diperoleh dU sebesar 1.724 dan dL yakni 1.413. Maka dapat diambil kesimpulan bahwa dU $<$ DW $<2$ atau $1.724<1.747<2$ yang berarti tidak terdapat aukorelasi positif maupun negatif.

\section{Uji Hipotesis}

Uji Koefisien Determinasi $\left(\mathbf{R}^{2}\right)$

Pengolahan data menggunakan uji ini untuk mengatur total jauh model dapat menerangkan variabel dependen berubah.

Tabel 6. Hasil Uji $\mathrm{R}^{2}$

\begin{tabular}{|l|c|c|c|c|}
\hline Model & $\mathrm{R}$ & $\begin{array}{c}\mathrm{R} \\
\text { Square }\end{array}$ & $\begin{array}{c}\text { Adjusted } \\
\text { R Square }\end{array}$ & $\begin{array}{c}\text { Std. Error of } \\
\text { the Estimate }\end{array}$ \\
\hline 1 & $.456^{\mathrm{a}}$ & .208 & .160 & 5587.63867 \\
\hline
\end{tabular}

Nilai Adjusted E Square yaitu 0.160 yang berarti hanya $16 \%$ variabel Pembiayaan Murabahah yang dipengaruhi variabel CAR, ROA dan NPF, namun sisanya yaitu $84 \%$ dipengaruhi variabel lainnya diluar penenlitian ini.

\section{Uji Simultan (Uji F)}

Uji ini menentukan seluruh variabel independen berupa model yang diinput dan variable dependen memiliki pengaruh secara bersama.

Tabel 7. Hasil Uji F

\begin{tabular}{|c|c|c|c|c|c|c|}
\hline \multicolumn{2}{|c|}{ Model } & Sum of Squares & Df & Mean Square & $\mathrm{F}$ & Sig. \\
\hline \multirow[t]{3}{*}{1} & Regression & 408799624.413 & 3 & 136266541.471 & 4.364 & $.008^{b}$ \\
\hline & Residual & 1561085294.504 & 50 & 31221705.890 & & \\
\hline & Total & 1969884918.918 & 53 & & & \\
\hline
\end{tabular}

Sumber : data sekunder diolah SPSS 2021

Pengujian mengenai Uji simultan dapat dilihat pada table 7 . F Fitung yaitu 4.364. Untuk mencari $\mathrm{F}_{\text {tabel }}$ dengan signifikan $5 \%$ yaitu :

- $\mathrm{df}_{1}=(\mathrm{k}-1)=3-1=2$

- $\mathrm{df}_{2}=(\mathrm{n}-\mathrm{k}-2)=55-3-1=51$

Jadi $\mathrm{F}_{\text {tabel }}$ didapatkan $(2: 51)=3.179$, dengan kata lain $F_{\text {hitung }} 4.364>3.179 \mathrm{~F}_{\text {tabel }}$. Dimana signifikansi $0.008<0.05$, jadi hasil yang didapat yakni hipotesis penelitian $\left(\mathrm{H}_{4}\right)$ yang diajukan peneliti menunjukkan bahwa CAR, ROA dan NPF berpengaruh pembiayaan murabahah.

\section{Uji Parsial (Uji t)}

Uji ini menunjukkan individual variabel independen dengan ragam variabel dependen dijelaskan. 
Tabel 8. Hasil Uji t

\begin{tabular}{l|l|r|r|r|r|r}
\hline \multicolumn{2}{l|}{} & \multicolumn{1}{c|}{ B } & Std. Error & Beta & & \\
\hline \multirow{3}{*}{1} & (Constant) & 1625.863 & 837.317 & & 1.942 & .058 \\
\cline { 2 - 7 } & LAG_X1 & -44.404 & 25.512 & -.242 & -1.741 & .088 \\
\cline { 2 - 7 } & LAG_X2 & 561.160 & 171.962 & .507 & 3.263 & .002 \\
\cline { 2 - 7 } & LAG_X3 & 354.400 & 650.070 & .088 & .545 & .588 \\
\hline
\end{tabular}

Untuk menentukan $t_{\text {tabel }}$ peneliti menggunakan uji 2 sisi dan untuk menentukan $t_{\text {tabel }}$ ialah : (sig. $\alpha=0.025$ dan $\left.d f=52\right) 2.007$. Maka hasil analisis penelitian dapat dilihat yaitu :

\section{Pengaruh variabel CAR $\left(\mathbf{X}_{1}\right)$ terhadap pembiayaan murabahah}

Didapatkan CAR mempunyai thitung sebesar -1.741 , berada pada area $\mathrm{H}_{\mathrm{O}}$ diterima serta signifikansi $0.088>0.05$. Jadi dapat diambil kesimpulan hipotesis $\mathrm{H}_{1}$ yang diajukan peneliti ditolak yang berarti CAR tidak pengaruh. Sama halnya pada penelitian (Wardiantika \& Kusumaningtias, 2014) yang menunjukkan CAR tidak berpengaruh pembiayaan murabahah di Bank Umum Syariah.

\section{Pengaruh variable $X_{2}$ terhadap pembiayaan murabahah}

Didapatkan ROA mempunyai thitung sebesar $3.263>2.007\left(\mathrm{t}_{\text {tabel }}\right)$ dengan tingkat signifikan $0.002<0.05$. Jadi dapat diambil kesimpulan $\mathrm{H}_{2}$ diterima yang menyatakan ROA berpengaruh terhadap pembiayaan murabahah. Hal tersebut sama dengan pernyataan (Murabahah et al., 2017) yang menyatakan ROA berpengaruh pada pembiayaan murabahah.

\section{Pengaruh NPF $\left(\mathrm{X}_{3}\right)$ terhadap pembiayaan murabahah}

Didapatkan NPF mempunyai thitung sebesar $0.545<2.007$ ( tabel) serta signifikansi $0.588>0.05$. Jadi dapat diambil kesimpulan $\mathrm{H}_{3}$ ditolak bahwasanya NPF tidak berpengaruh terhadap pembiayaan murabahah. Hal tersebut sesuai dengan penelitian (Aziza \& Mulazid,
2017) bahwasanya NPF tidak berpengaruh pada pembiayaan murabahah.

\section{KESIMPULAN}

Berdasarkan pembahasan diatas, maka bisa disimpulkan bahwa CAR tidak berpengaruh terhadap pembiayaan murabahah pada bank umum syariah di Indonesia. NPF tidak berpengaruh terhadap pembiayaan murabahah pada bank umum syariah di Indonesia. ROA berpengaruh signifikan terhadap pembiayaan murabahah pada bank umum syariah di Indonesia. Sedangkan CAR, ROA dan NPF secara simultan berpengaruh signifikan terhadap pembiayaan murabahah pada bank umum syariah di Indonesia.

\section{DAFTAR PUSTAKA}

Abbas, D. (2018). Pengaruh Current Ratio, Account Receivable Turnover, Inventory Turnover, Total Asset Turnover dan Debt To Equity terhadap Return on Asset (Pada Perusahaan Sub Sektor Otomotif dan Komponen yang Terdaftar di Bursa Efek Indonesia Periode 2011-2014). Competitive Jurnal Akuntansi Dan Keuangan, Vol 2, No.

Aziza, R. V. S., \& Mulazid, A. D. E. S. (2017). Analisis Pengaruh Dana Pihak Ketiga, Non Performing Financing, Capital Adequacy Ratio, Modal Sendiri Dan Marjin Keuntungan Terhadap Pembiayaan Murabahah. Jurnal Ekonomi Dan Bisnis Islam (JEBI), 2(1), 1-15.

Mahardika, D. P. K. (2015). Mengenal Lembaga Keuangan. Gratama Publishing.

Mizan. (2017). Car, Npf, Der, Dan Roa Terhadap 
Pembiayaan Murabahah Pada Bank Umum Syariah. Balance.

Murabahah, P., Syariah, P., \& Indonesia, D. I. (2017). No Title.

Nafidzatun, N., Hulaikhah, M., \& Arif, A. (2020). Pengaruh Car, Npf Dan Fdr Terhadap Pembiayaan Murabahah Pada Bank Umum Syariah Di Indonesia. Jurnal Ekonomi Syariah, 5(2), 140-152.

Nahrawi, A. A. (2017a). Pengaruh Capital Adequacy Ratio (CAR), Return On Assets (ROA) dan Non Performing Financing (NPF) Terhadap Pembiayaan Murabahah BNI Syariah. Perisai : Islamic Banking and Finance Journal. https://doi.org/10.21070/perisai.v1i2.881

Nahrawi, A. A. (2017b). Pengaruh Capital Adequacy Ratio (CAR), Return On Assets (ROA) dan Non Performing Financing (NPF) Terhadap Pembiayaan Murabahah BNI Syariah. Perisai : Islamic Banking and Finance Journal, 1(2), 141. https://doi.org/10.21070/perisai.v1i2.881

Nurhayati, S., \& Wasilah. (2019). Akuntansi Syariah di Indonesia (5th ed.). Salemba Empat.

Risiko, D. A. N., Terhadap, M., Pada, C. A. R., Umum, B., Di, T., \& Periode, B. E. I. (2015). PENGARUH ROA, SIZE, RISIKO
LIKUIDITAS, RISIKO KREDIT, RISIKO SUKU BUNGA, DAN RISIKO MODAL TERHADAP CAR PADA BANK UMUM YANG TERDAFTAR DI BEI PERIODE 2008 - 2013 Fredy Herman Yunialdo, Prasetiono 1. 4(10), 1-12.

Sa'diyah, M. (2019). Strategi Penanganan Non Performing Finance (Npf) Pada Pembiayaan Murabahah Di Bmt. Conference on Islamic Management Accounting and Economics, 2, 179-189.

Setyaji, A. K. (2018). Analisis faktor penjelas pendapatan margin. Jurnal Fakultas Ekonomi Islam, M, 559-568.

Simatupang, H. B. (2019). Peranan perbankan dalam meningkatkan perekonomian indonesia. Jurnal Riset Akuntansi Multiparadigma, 6(2), 136-146.

Studi, B., Bank, P., Swasta, U., Yang, D., Di, T., \& Hidayati, L. N. (2013). Pengaruh Kecukupan Modal ... 38-50.

Wardiantika, L., \& Kusumaningtias, R. (2014). Pengaruh Dpk, Car, Npf, Dan Swbi Terhadap Pembiayaan Murabahah Pada Bank Umum Syariah Tahun 2008-2012. Ifstin Jurnal Ilmu Manajemen (JIM), 2(4), 1550-1561.

http://jurnalmahasiswa.unesa.ac.id/index.php /jim/article/view/11151 